\title{
Urachal yolk sac tumor penetrating the bladder as a diagnostic challenge: a case report and review of the literature
}

\author{
Vladimír Šámal ${ }^{1,2^{*}} \mathbb{B}$, Tomáš Jirásek ${ }^{3}$, Vít Paldus ${ }^{1}$, Igor Richter ${ }^{4,5}$ and Ondřej Hes ${ }^{6}$
}

\begin{abstract}
Background: Yolk sac tumor (YST) is a germ cell tumor. It is primarily located in the gonads but can also occur extragonadally (extragonadal yolk sac tumor - EGYST), most commonly in the pelvis, retroperitoneum or mediastinum. Only a few YSTs of the urachus have been described.

Case report: We present a rare case report of a 37-year-old male with episodes of macroscopic hematuria. The histological specimen obtained by transurethral resection showed a solid, and in some parts papillary infiltrative, high-grade tumor with numerous areas of marked nuclear atypia and clear invasion between the detrusor bundles. Glandular pattern has been observed in only minority of the tumor. Immunohistochemistry showed significant positivity for GPC3, SALL4 and cytokeratins AE1/AE3, while KRT7 and GATA3 were negative. We concluded that the biopsy findings were consistent with urothelial carcinoma with infrequent YST differentiation. In definitive surgical specimens we found a malignant epithelial, glandular and cystically arranged tumor of germinal appearance arising from urachus. The surrounding urothelium was free of invasive or in situ tumor changes. We reclassified the tumor as a urachal YST.
\end{abstract}

Conclusion: EGYST was suspected because glandular and hepatoid structures were found, but the presence of these structures should be verified by immunohistochemistry.

Keywords: Extragonadal yolk sac tumor, Urachal yolk sac tumor, Yolk sac tumor

\section{Introduction}

Yolk sac tumor (YST) is a type of germ cell tumor that originates predominantly in the gonads. However, it can also occur extragonadally (extragonadal yolk sac tumor EGYST). Extragonadal forms represent $1-5 \%$ of germ cell tumors and are considered to be a consequence of the incorrect migration of germ cells during embryogenesis [1]. The incidence of EGYST is $1.8-3.4 / 1$ million people, affecting males and Caucasians more often [2].

\footnotetext{
* Correspondence: vladimir.samal@nemlib.cz

'Department of Urology, Krajská Nemocnice Liberec a.s, Liberec, Czech Republic

${ }^{2}$ Department Of Urology, Faculty of Medicine in Hradec Králové, Charles University, Prague, Czech Republic

Full list of author information is available at the end of the article
}

The most common extragonadal locations of YST include the pelvis, retroperitoneum, and mediastinum [3-5]. In a number of somatic tumors, YST differentiation can be observed in some parts of the tumor, and somatic derivation of YST has been considered. The most common tumors with YST differentiation include adenocarcinomas, immature teratomas and serous carcinomas in the pelvic, sacrococcygeal and gastrointestinal regions $[4,6]$.

The urachus is a remnant of the embryonic structure connecting the bladder to the umbilicus that is present in adulthood. Tumors of the urachus are rare, and the most common tumor type is adenocarcinoma. Only a few cases of primary YST of the urachus have been described [7-10]. 
This case report presents the diagnostic challenge of EGYST penetrating into the bladder.

\section{Case report}

A 37-year-old man, who was otherwise healthy, suffered episodes of macroscopic hematuria. A solid polypoid tumor of $30 \mathrm{~mm}$ in diameter was evident in the bladder dome during the cystoscopy examination. A CT scan showed an exophytic tumor in the bladder dome infiltrating the perivesical fat (Fig. 1). We performed diagnostic transurethral resection. Macroscopically, the tumor was mostly solid and rigid on resection with small areas of necrosis. The tumor did not have the macroscopic appearance typical of urothelial carcinoma.

Histologically, the specimen contained multiple, partially thermally bruised areas, most of which consisted of solid and in places papillary infiltrative tumor components. The tumor contained numerous areas with prominent nuclear atypia and distinct invasion into the subepithelial connective tissue and between the trapped bundles of detrusor smooth muscle. The tumor showed necrotic foci and some of the tumor cells showed clear cytoplasm, with conspicuous eosinophilic globules in places. A glandular tumor pattern was present in up to
$5 \%$ of areas. Based on the microscopic appearance on HE sections we concidered so-called variant histology within the spectrum of urothelial carcinoma before receiving the immunohistochemistry results.

Immunohistochemically, the tumor expressed glypican3 (GPC3), SALL4, broad-spectrum keratins (AE1/AE3) and alpha-fetoprotein (AFP). The tumor showed localized expression of synaptophysin and CDX2 (Fig. 2). The tumor was negative for epithelial membrane antigen (EMA), HepPar1, vimentin, keratin7, placental-like alkaline phosphatase (PLAP), CD117, CD30, OCT3/4, hCG, p63, and GATA-3.

The serum AFP level was $446 \mathrm{kU} / \mathrm{L}$ (normal range 0.7$7.3 \mathrm{kU} / \mathrm{L}$ ), and the hCG and LD levels were within the normal ranges. The sonography findings on the testes showed no tumor changes or calcifications. Fluorescence in situ hybridization (FISH) using locus-specific probes for NTF3 (12p13) and STAT6 (12q13) (SureFISH Agilent Technologies, Santa Clara, CA, USA) showed no gains in chromosome 12p. The presence of isochromosome was not tested.

Due to atypical changes suggestive of diagnosis of urothelial carcinoma and foci of YST differentiation the tumor was histologically classified as high-grade urothelial carcinoma with YST differentiation.

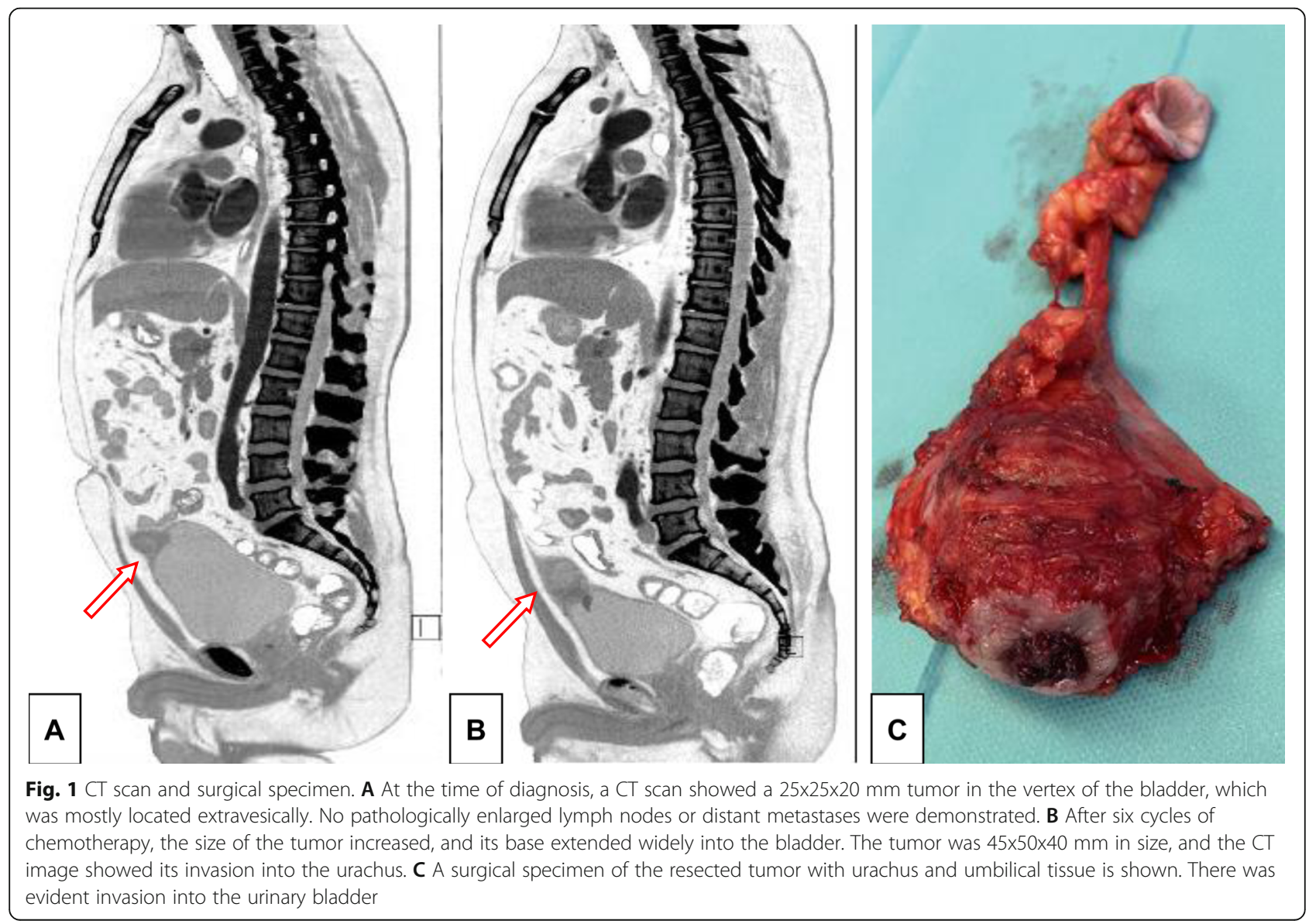




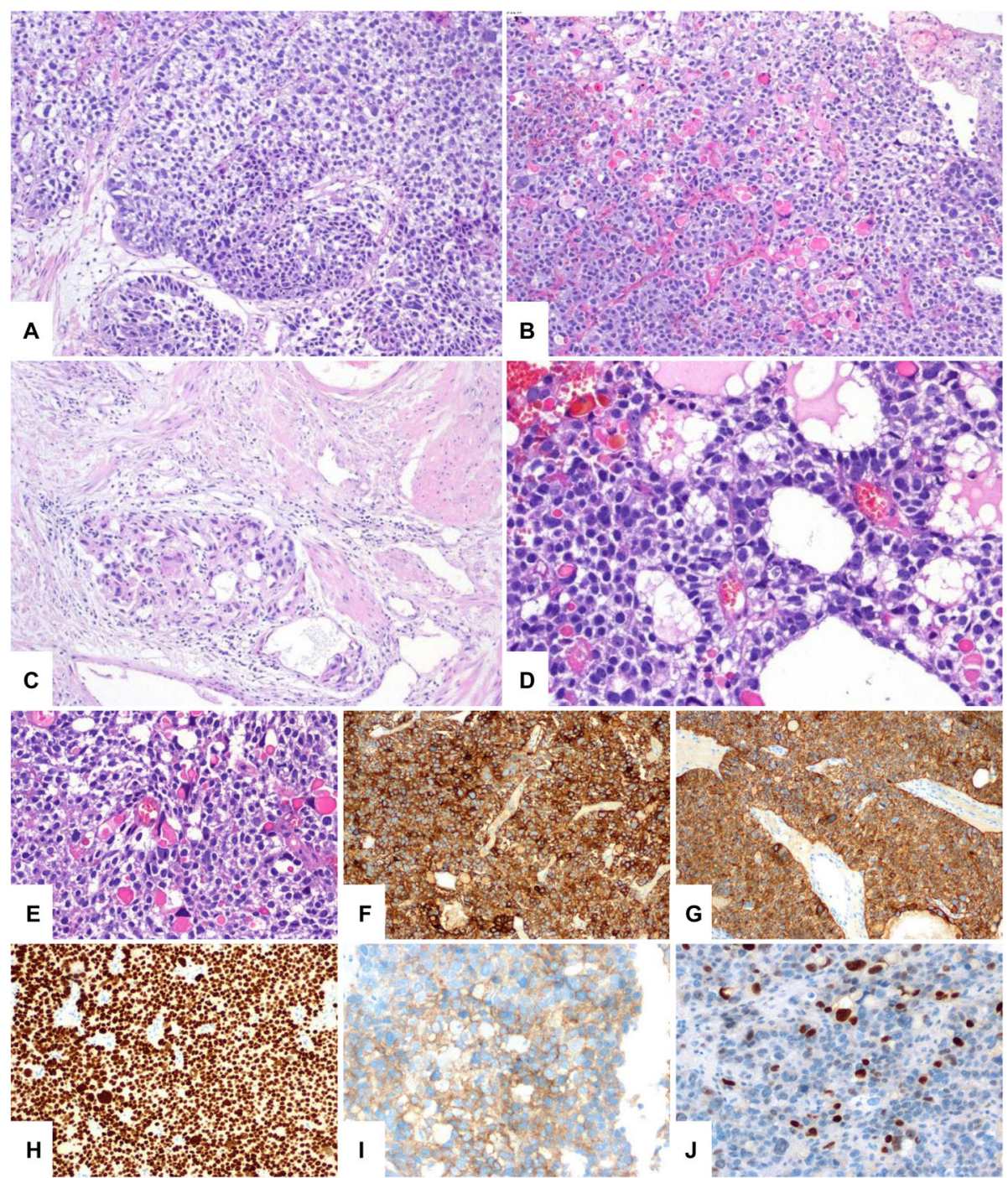

Fig. 2 A Superficial areas of the resected tumor showed urothelial carcinoma with papillary morphology. B Different parts of similar tumors are shown, including solid and adenoid areas with clear cells and hyaline globules (stars). C Carcinoma nests were found among smooth muscle fascicles of the bladder wall. D There were glandular formations within the tumor. E There were clear cells and hyaline globules. Immunostaining: (F) Glypican-3 was present in tumor cells. G Keratins AE1/AE3 were present in tumor cells. H SALL4 was present in tumor cell nuclei. I AFP was present in tumor cells. $\mathbf{J}$ CDX2 was present in tumor cell nuclei

The patient refused surgery and was treated with etoposide/cisplatin (EP) chemotherapy. After 2 cycles of EP, the AFP level rose to $2294 \mathrm{kU} / \mathrm{L}$. The chemotherapy regimen was changed to the paclitaxel/ifosfamide/cisplatin (TIP) salvage regimen. After 4 cycles of TIP, the tumor size increased according to control CT. The AFP level plateaued at $2034 \mathrm{kU} / \mathrm{L}$. Control cystoscopy showed an exulcerated lesion in the bladder dome bordered by a minimal circumscribed rim of reddened mucosa. Ultimately, resection of the bladder dome, urachus and umbilicus was performed 6 months after the diagnosis (Fig. 1).

Tumor was localized in the distal part of the urachus and penetrated the bladder dome. A malignant epithelial tumor with a pattern typical of YST, mainly glandular and with a cystic arrangement, was noted. Satellite foci of the same tumor were observed outside the main tumor mass. The transition from the urothelium to the YST in an excised part of the bladder was very abrupt, without any dysplasia or in situ changes in the urothelium (Fig. 3). We observed positive staining for SALL4 and GPC3. The tumor showed positive staining for keratins (AE1/AE3), and the intensity of the staining reaction was mostly strong within the cytoplasm of neoplastic cells; however, small foci of cells with weaker staining positivity were also detected within the tumor mass.

Immunostaining for GATA3, OCT3/4, KRT 7, chromogranin A and synaptophysins was negative. FISH did not detect any gain in the $12 \mathrm{p}$ region. 


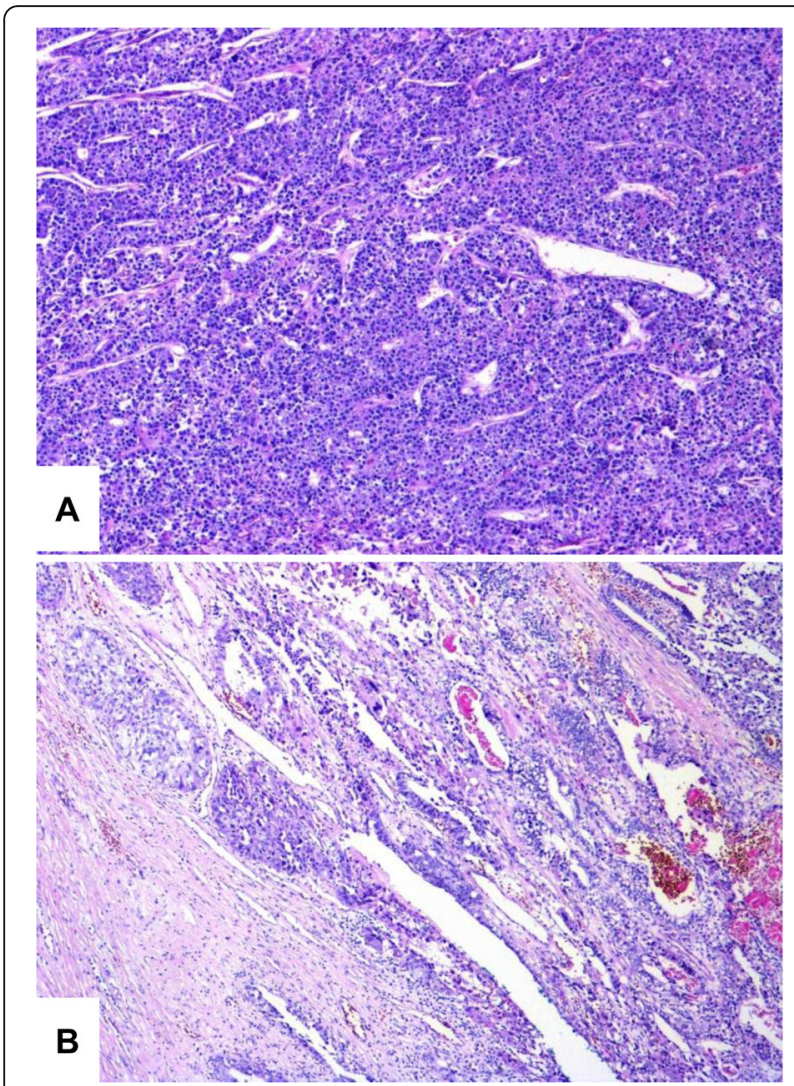

Fig. 3 A Histological findings from the resected tumor specimen showed a solid trabecular, sporadically glandular and cystically arranged malignant tumor of germinal appearance. B The transition to urothelium was abrupt, without any dysplasia or in situ change of the urothelium

Based on these findings, we reclassified the tumors as EGYST penetrating into the bladder. Six months after treatment, the patient had no evidence of disease recurrence on CT and serum AFP levels were within the normal range.

\section{Discussion}

The initial histology findings obtained from transurethral resection showed both solid and papillary tumor components, invasion between the detrusor bundles and a focal glandular component that showed GPC3, SALL4, and AFP positivity. The presence of papillary tumor changes imitating urothelial tumor and YST structures led us to a working diagnosis of urothelial carcinoma with YST differentiation. The definitive histological findings obtained after surgery caused us to correct the diagnosis to EGYST, and the tissue surrounding the urothelium and the urothelium itself were free of tumor changes. Atypical changes suggestive of the diagnosis of urothelial carcinoma were later interpreted as reactive.

The histological variability of YST and its ability to mimic somatic tumors may cause diagnostic difficulties
[11]. Compared with other germ cell tumors, YST presents very varied and diverse histological findings. In particular, its occurrence in extragonadal locations and outside the typical age range cause diagnostic challenges. YST can occur anywhere along the midline. From a urogenital pathology perspective, involvement of the renal pelvis [6], prostate [12], seminal vesicle [13], bladder [14, 15], and retroperitoneum [5] is known. YSTs are highly aggressive tumors that can metastasize lymphatically and hematogenously. EGYSTs occur at various ages with a tendency for a worse prognosis with increasing age. Typically, EGYSTs manifest in childhood and in young women [11]. The patient presented in our case report was 37 years of age. Only one case of urachal YST reported thus far involved a patient aged 44 years [9]. In the rest of the reported cases, the patients were children under 2 years of age $[7,10]$.

YST differentiation of somatic tumors is relatively rare, and reported cases of YST differentiation of urothelial tumors are even less common $[6,16,17]$. Histologically, tumors can contain both YST and somatic tumor structures. The YST component corresponds to the germ cell tumor, and it is not uncommon for the YST component to grow larger than the somatic tumor component due to its higher proliferative activity [18]. Somatic malignancies with YST differentiation are characterized by the presence of different patterns, the most typical being the glandular pattern [1]. In our case, solid and papillary patterns were the main patterns found in the biopsy. The glandular pattern that is usually described as typical for YST differentiation was observed only focally (Fig. 2). There are available data on AFP-producing urothelial tumors [19-21]. Most of these tumors present hepatoid tissue areas in the context of adenocarcinoma or urothelial carcinoma and show AFP positivity. In our case, no area with a hepatoid pattern similar to that in the YST were observed. Samaratunga et al. published a case report of urothelial carcinoma of the renal pelvis with focal hepatoid adenocarcinoma differentiation, and the tumor showed strong AFP immunoreactivity and serum AFP positivity [16]. There are also documented cases of bladder adenocarcinomas that have shown both immunoreactivity for AFP and elevated serum AFP levels [16]. Recently, a case of urothelial tumor with YST differentiation was presented by Espejo-Herrera et al. The patient was a 76-year-old male with a history of recurrent urothelial carcinoma of the bladder [17].

In addition to the abovementioned microscopic features, immunohistochemical methods are essential for accurate diagnosis. Extragonadal tumors usually show the same immunoreactivity as their gonadal counterparts [11]. AFP and GPC3 are characteristic immunohistochemical markers of YST, which may correlate with their serum levels $[1,22]$. Some stem and pluripotent 
cell antigens (SALL4, Lin28 or IMP3) may also be helpful in diagnosis.

AFP remains the standard marker for YST, even though it can also be produced by several non-germ cell tumors, especially those of the female genital tract, and tumors of endodermal origin with a frequent hepatoid component [1]. AFP staining shows strong granular cytoplasmic positivity, and AFP may also be expressed in hyaline globules, although this is not always present [1]. Determination of serum AFP is useful in the diagnosis and follow-up of patients with YST or EGYST.

Most YSTs show positivity for AFP, GPC3 and SALL4 [23-25]. In contrast, most differentiated epithelial markers, such as EMA and KRT17 shows negative reactions. Inconsistent results were shown for the markers HepPar1, which may be positive in hepatoid pattern regions, and CDX2, which may be positive in glandular pattern regions of the tumor. There has also been a report of pure urothelial carcinoma with SALL4 positivity [26]. Most published case reports of urachal YSTs, including our case report, reported positivity for at least AFP and keratins $[8,9]$.

Genetic alterations are common in germ cell tumors, including isochromosome 12p, p53 alteration, and other changes [27, 28]. We did not find a gain of $12 p$ when we tested for numerical changes in the 12p region by FISH. Extragonadal germ cell tumors do not appear to share a common genetic basis with their gonadal counterparts.

Prognostically, extragonadal forms of germ cell tumors are significantly worse than those in the gonads [29]. Tumors with a YST component are diagnosed at a younger age and may be more likely to be pure EGYSTs [6]. The determination of whether a tumor is EGYST or a somatic tumor with YST differentiation also has a major impact on therapy. While most gonadal YSTs respond relatively well to chemotherapy, a benefit of chemotherapy for EGYST is more likely to be seen in younger patients. The benefit of chemotherapy for somatic tumors with YST differentiation is unclear [6]. In the case of advanced or metastatic germ cell cancer, cisplatin-based chemotherapy is the mainstay. Five-year survival rates range from 40 to $90 \%$, with a more favorable prognosis for seminomas or retroperitoneal tumors than for nonseminomas or mediastinal tumors [29].

This case includes a rare presentation of urachal EGYST. Chemotherapy was not associated with the achievement of a curative response. Remission was achieved only after radical surgery. The finding of glandular and hepatoid structures in the tumor is suspicious for EGYST. Serum AFP marker positivity may be an advantage. Suspicion of EGYS $\mathrm{T}$ should be verified by immunohistochemistry.

\section{Abbreviations}

YST: Yolk sac tumor; AFP: Alpha fetoprotein; GPC3 : Glypican 3; SALL4: Sal-like protein 4; AE1/AE3: Keratin AE1/AE3; CDX2: Caudal type homeobox 2;
EMA: Epithelial membrane Antigen; HepPar 1: Hepatocyte Paraffin 1; OCT3/ 4: Octamer binding transcription factor 3/4; KRT7: Keratin7; PLAP: Placental alkaline phosphatase; CD117: Monoclonal anti-human CD117; CD30: Monoclonal mouse anti-human CD30; hCG: Human chorionic gonadotropin; p63: Transformation-related protein 63.; GATA3: GATA binding protein 3; 12p: Short arm of chromosome 12; NTF3: Neurotrophin 3; STAT6: Signal transducer and activator of transcription 6

\section{Authors' contributions}

Study concepts and desing: VŠ, IR. Histologic analysis and interpertation: TJ, $\mathrm{OH}$. Manuscript preparation: VŠ, VP. Manuscript review: VŠ, IR, TJ, OH. All authors read and approved the final manuscript.

\section{Funding}

No funding has been gained by the authors for this research.

\section{Availability of data and materials}

All generated or analyzed during this study are included in this article.

\section{Declarations}

Ethics approval and consent to participate

This paper was reviewed for publication by the by the relevant Institutional Review Boards and informed consent with publication was obtained.

Consent for publication

All authors consent to the publication of the manuscript in Diagnostic Pathology.

\section{Competing interests}

The authors declare no conflict of interest.

\section{Author details}

${ }^{1}$ Department of Urology, Krajská Nemocnice Liberec a.s, Liberec, Czech Republic. ${ }^{2}$ Department Of Urology, Faculty of Medicine in Hradec Králové, Charles University, Prague, Czech Republic. ${ }^{3}$ Department of Pathology, Krajská Nemocnice Liberec, a.s, Liberec, Czech Republic. ${ }^{4}$ Department of Oncology, Krajská Nemocnice Liberec, a.s, Liberec, Czech Republic. ${ }^{5}$ Department of Oncology, First Faculty of Medicine, Charles University and Thomayer Hospital, Prague, Czech Republic. ${ }^{6}$ Charles University and University Hospital Pilsen, Pilsen, Czech Republic.

Received: 24 June 2021 Accepted: 30 December 2021

Published online: 14 January 2022

\section{References}

1. Nogales FF, Preda O, Nicolae A. Yolk sac tumours revisited. A review of their many faces and names. Histopathology. 2012;60(7):1023-33.

2. Stang A, Trabert B, Wentzensen N, Cook MB, Rusner C, et al. Gonadal and extragonadal germ cell tumours in the United States, 1973-2007. Int J Androl. 2012;35(4):616-25

3. Moran CA, Suster S, Koss MN. Primary germ cell tumors of the mediastinum: III. Yolk sac tumor, embryonal carcinoma, choriocarcinoma, and combined nonteratomatous germ cell tumors of the mediastinum--a clinicopathologic and immunohistochemical study of 64 cases. Cancer. 1997;80(4):699-707.

4. McNamee T, Damato S, McCluggage WG. Yolk sac tumours of the female genital tract in older adults derive commonly from somatic epithelial neoplasms: somatically derived yolk sac tumours. Histopathology. 2016; 69(5):739-51.

5. Guo YL, Zhang YL, Zhu JQ. Primary yolk sac tumor of the retroperitoneum: a case report and review of the literature. Oncol Lett. 2014;8(2):556-60.

6. Ravishankar S, Malpica A, Ramalingam P, Euscher ED. Yolk sac tumor in Extragonadal pelvic sites: still a diagnostic challenge. Am J Surg Pathol. 2017:41(1):1-11.

7. Suma TL, Ramanathan S, Padma M, Appaji L, Suma MN. A case of Urachal yolk sac tumor with spontaneous rupture in a child. J Pediatr Hematol Oncol. 2017;39(2):e82-4.

8. Huang HY, Ko SF, Chuang JH, Jeng YM, Sung MT, et al. Primary yolk sac tumor of the urachus. Arch Pathol Lab Med. 2002;126(9):1106-9. 
9. Romero-Rojas AE, Messa-Botero OA, Melo-Uribe MA, Díaz-Pérez JA, Chinchilla-Olaya SI. Primary yolk sac tumor of the urachus. Int I Surg Pathol. 2011;19(5):658-61.

10. D'Alessio A, Verdelli G, Bernardi M, DePascale S, Chiarenza SF, et al. Endodermal sinus (yolk sac) tumor of the urachus. Eur J Pediatr Surg. 1994; 4(3):180-1.

11. McKenney JK, Heerema-McKenney A, Rouse RV. Extragonadal germ cell tumors: a review with emphasis on pathologic features, clinical prognostic variables, and differential diagnostic considerations. Adv Anat Pathol. 2007; 14(2):69-92.

12. Furr JR, Mellis AM, Slobodov G. Primary yolk sac tumor of the prostate: a case report and review of the literature. Urol Int. 2015;95(2):240-2.

13. Yao XD, Hong YP, Ye DW, Wang CF. Primary yolk sac tumor of seminal vesicle: a case report and literature review. World J Surg Oncol. 2012;10:189.

14. Taylor G, Jordan M, Churchill B, Mancer K. Yolk sac tumor of the bladder. J Urol. 1983;129(3):591-4.

15. Mui WH, Lee KC, Chiu SC, Pang CY, Chu SK, et al. Primary yolk sac tumour of the urinary bladder: a case report and review of the literature. Oncol Lett. 2014;7(1):199-202.

16. Samaratunga H, Samaratunga D, Dunglison N, Perry-Keene J, Nicklin J, et al. Alpha-fetoprotein-producing carcinoma of the renal pelvis exhibiting hepatoid and urothelial differentiation. Anticancer Res. 2012;32(11):4987-91.

17. Espejo-Herrera N, Condom-Mundó E. Yolk sac tumor differentiation in urothelial carcinoma of the urinary bladder: a case report and differential diagnosis. Diagn Pathol. 2020;15(1):68.

18. García-Galvis OF, Cabrera-Ozoria C, Fernández JA, Stolnicu S, Nogales FF. Malignant Müllerian mixed tumor of the ovary associated with yolk sac tumor, neuroepithelial and trophoblastic differentiation (teratoid carcinosarcoma). Int J Gynecol Pathol. 2008;27(4):515-20.

19. Takayama H. A case of bladder cancer producing alpha-fetoprotein (AFP). Hinyokika Kiyo. 1995;41(5):387-9.

20. Lu CH, Chou WC, Hung YS, Yeh KY, Sheu S, et al. Alpha-fetoproteinproducing transitional cell carcinoma of the urinary bladder: a case report. Int Urol Nephrol. 2009;41(3):567-70.

21. Sakata Y, Onishi T, Yamada Y, Arima K, Yanagawa M, et al. Alpha-fetoprotein producing renal pelvic and ureter tumor. J Urol. 2001;166(5):1830.

22. Liu H, Li P, Zhai Y, Qu CF, Zhang LJ, et al. Diagnostic value of glypican-3 in serum and liver for primary hepatocellular carcinoma. World J Gastroenterol. 2010;16(35):4410-5.

23. Preda O, Nicolae A, Aneiros-Fernández J, Borda A, Nogales FF. Glypican 3 is a sensitive, but not a specific, marker for the diagnosis of yolk sac tumours. Histopathology. 2011;58(2):312-4 author reply 314-5.

24. Liu A, Cheng L, Du J, Peng Y, Allan RW, et al. Diagnostic utility of novel stem cell markers SALL4, OCT4, NANOG, SOX2, UTF1, and TCL1 in primary mediastinal germ cell tumors. Am J Surg Pathol. 2010;34(5):697-706.

25. Bing Z, Pasha T, Tomaszewski JE, Zhang P. CDX2 expression in yolk sac component of testicular germ cell tumors. Int J Surg Pathol. 2009;17(5):373-7.

26. Miettinen M, Wang Z, McCue PA, Sarlomo-Rikala M, Rys J, et al. SALL4 expression in germ cell and non-germ cell tumors: a systematic immunohistochemical study of 3215 cases. Am J Surg Pathol. 2014;38(3): 410-20.

27. Bosl GJ, Motzer RJ. Testicular germ-cell cancer. N Engl J Med. 1997;337(4): 242-53.

28. Loveday C, Litchfield K, Levy M, Holroyd A, Broderick P, et al. Validation of loci at 2q14.2 and 15q21.3 as risk factors for testicular cancer. Oncotarget. 2018;9(16):12630-8.

29. Bokemeyer C, Nichols CR, Droz JP, Schmoll HJ, Horwich A, et al. Extragonadal germ cell tumors of the mediastinum and retroperitoneum: results from an international analysis. J Clin Oncol. 2002;20(7):1864-73.

\section{Publisher's Note}

Springer Nature remains neutral with regard to jurisdictional claims in published maps and institutional affiliations.

Ready to submit your research? Choose BMC and benefit from:

- fast, convenient online submission

- thorough peer review by experienced researchers in your field

- rapid publication on acceptance

- support for research data, including large and complex data types

- gold Open Access which fosters wider collaboration and increased citations

- maximum visibility for your research: over $100 \mathrm{M}$ website views per year

At BMC, research is always in progress.

Learn more biomedcentral.com/submissions 